\title{
Sarı Uygurca Üzerine Etimolojik Denemeler: U-Ü Maddeleri
}

\section{Etymological Attempts on Yellow Uyghur: U-Ü Items}

\author{
Özlem Ayazl1 ${ }^{1}$ (1)
}

'Doç. Dr., Sivas Cumhuriyet Üniversitesi, Edebiyat Fakültesi, Türk Dili ve Edebiyatı Bölümü, Sivas, Türkiye

ORCID: Ö.A. 0000-0003-4981-6900

Sorumlu yazar/Corresponding author: Özlem Ayazlı,

Sivas Cumhuriyet Üniversitesi, Edebiyat Fakültesi, Türk Dili ve Edebiyatı Bölümü, Sivas, Türkiye

E-mail: civelek.o@gmail.com

Başvuru/Submitted: 01.05.2019

Revizyon Talebi/Revision Requested: 12.06.2019 Son Revizyon/Last Revision Received: 24.06.2019 Kabul/Accepted: 25.06.2019

Online Yayın/Published Online: 28.06.2019

\section{Atıf/Citation:}

Ayazli, O. (2019). Sarı Uygurca üzerine etimolojik denemeler: U-Ü maddeleri. TUDED 59(1), 1-26.

https://doi.org/10.26650/TUDED2019-0007

\section{ÖZET}

$\mathrm{Bu}$ çalışmanın amacı, ileride tarafimdan tamamlanması düşünülen Sarı Uygurca etimolojik sözlüğün "U-Ü" maddelerine katkı sağlamaktır. Bu amaçla, 1957 yılında Sergey Yefimoviç Malov'un yayımladığı Yazık jyoltıh uygurov: Slovar' i grammatika ve 1976 yılında Tenişev'in yayımladığı Stroy sarıg-yugurskogo yazıka adlı çalışmalarının "U-Ü" maddeleri incelenmiștir. Söz konusu çalışmaların sözlük bölümlerindeki maddeler ve madde içerisindeki cümle örnekleri Türkiye Türkçesine çevrilmiş, çeviri yapıldıktan sonra sözcüklerle ilgili etimolojiler verilmiştir. Sözcükler hem tarihî hem de modern Türk dilleri ile karşılaştırılmıștır. "U-Ü" maddelerine ait toplam 197 sözcük tespit edilmiștir. Sarı Uygurca sözlüklerin "U-Ü" maddeleri çerçevesinde diğer Türk dilleri ile yapılan karşılaştırma sonucunda ortaya çıkan veriler ise şöyledir: Sarı Uygurca ile Kuzey ve Güney Sibirya Türk dillerinde 12 ortak sözcük tespit edilmiştir. Tespit edilen bu sözcükler şunlardır: ulğak, ulug, uttur, uza-, uzruk, uzun, üç, üçür-, üleș-, ürek, ürgen-, ürget-. Sar1 Uygurca söz varlığının 32'si Hakasçada, 30'u Altaycada, 27'si Tuvacada, 18'i de Yakutçada saptanmıştır. Ortaya çıkan bu veri yaklaşık değerleri içermekle birlikte Sarı Uygurcanın Güney Sibirya dilleri ile yakından ilgili olduğunu teyit etmektedir. "U-Ü" maddelerinin söz varlığı doğrultusunda bütün modern dillerde ya da dil gruplarında kimi ses değişikleri ile görülen 23 ortak sözcük belirlenmiştir: uç, uç-, ula-, ulgak, ulug, ulus II, unut-, ürk-, ürküt-, uttur, uza-, uzun, uzut-, üç, üçür-, ülem, ülis-, ürek, ürgen-, ürget-, üy, üz-, üzge.

Anahtar Kelimeler: Sarı Uygurca, etimoloji, Eski Türkçe, tarihî ve modern Türk dilleri

\section{ABSTRACT}

The aim of this paper is to contribute to the "U-Ü" items of Yellow Uyghur etymological dictionary which I plan to complete in the future. For this purpose, "U-Ü" items were investigated in Yazık jyoltı h uygurov: Slovar' 'i grammatika published by Sergey Yefimoviç Malov in 1957 and Stroy sarı-yugurskogo yazlka published by Tenişev in 1976. Items of dictionary parts and sentence examples in the items that were taken from these studies were translated into Turkish and etymologies about the words were listed. Then those words were compared with both historical and modern Turkic languages. A total of 197 words were identified in "U-Ü" items. The results of this comparison "U-Ü" items of Yellow Uyghur dictionaries with the other Turkic languages are as follows: 12 common words were identified in Yellow Uygur and North-South Siberian Turkic languages. These words are as follows: ulğak, ulug, uttur, uza-, uzruk, uzun, üç, üçür-, üleş-, ürek, ürgen-, ürget-. It was found that Yellow Uyghur words were detected in some languages, such as 32 of them in Khakas, 30 of them in Altay, 27 of them in Tuvanian and 18 of them in Yakut. This data containing approximate value confirms that Yellow Uyghur is closely related to South Siberian Turkic languages. It was determined 23 common words which are seen with some sound changes in all modern languages or languages groups in accordance with vocabulary of "U-Ü" items: uç, uç-, ula-, ulgak, ulug, ulus II, unut-, ürk-, ürküt-, uttur, uza-, uzun, uzut-, üç, üçür-, ülem, ülis-, ürek, ürgen-, ürget-, üy, üz-, üzge. Keywords: Yellow Uyghur, etymology, Old Turkic, historical and modern Turkic languages 


\section{EXTENDED ABSTRACT}

The aim of this paper is to contribute to the "U-Ü" items of Yellow Uyghur etymological dictionary which I plan to complete in the future. This study, which is called "Etymological Attempts on Yellow Uyghur: "U-Ü" Items", is a continuation of the paper called "Etymological Attempts on Yellow Uyghur" (Ayazl1, 2016: 290-313) previously published by me. "A" item of the dictionaries of S. Y. Malov and E. R. Tenişev was emphasized on the first article published in 2016. "E" (2017: 1320-1338) and "Ï-I" (2017: 148-171) items of these dictionaries were included in other publications published in 2017. My purpose is to prepare for publication vowel-items in dictionaries of Sergey Yefimoviç Malov and E. Rahimoviç Tenişev. Thefore, in this study "U-Ü” items are investigated. This paper was organized in three parts. The first part is the introduction which gives brief information about the methodology. In the second part, "U-Ü" items are investigated in Yazı jyoltıh uygurov: Slovar' i grammatika published by S. Y. Malov in 1957 and Stroy sarlg-yugurskogo yazıka published by E. R. Tenişev in 1976. The items of dictionary parts and sentence examples in the items that were taken from these studies were translated into Turkish and etymologies about the words were listed. As the subject of this paper is to create an etymological dictionary on Yellow Uyghur, the forms and meanings in Old Turkic and other historical modern periods of Turkish words were also analyzed. Then those words were compared with both historical and modern Turkic languages. Etymologies made by S. Y. Malov and E. R. Tenişev or other researchers in several times were also included in to the paper. The final part of the study conludes with the conclusion part where the data obtained is listed. These conclusions are as follows:

- A total of 197 words were identified in "U-Ü" items. 135 of these words are belong to "U" item and 62 of them "Ü" item. The results of this comparison "U-Ü" items of Yellow Uyghur dictionaries with the other Turkic languages are as follows: 12 common words were identified in Yellow Uygur and North-South Siberian Turkic languages. These words are as follows: ulğak "kid goat", ulug "big, great", uttur "before, opposite", uza- "to lengthen", uzruk "fist", uzun "long", üç "three", üçür- "to abolish", ülis- "to be divide", ürek "heart", ürgen- "to learn", ürget- "to teach". Yellow Uyghur words were detected in some languages, such as 32 of them in Khakas, 30 of them in Altay, 27 of them in Tuvanian and 18 of them in Yakut. This data containing approximate value confirms that Yellow Uyghur is closely related to South Siberian Turkic languages.

- It was determined that 23 common words which are seen with some sound changes in all modern languages or languages groups in accordance with vocabulary of "U-Ü" items: $u c ̧$ "end, tip", uç- "to fly", ula- "to join", ulgak "kid goat", ulug "big", ulus II "share, part", unut"to forget", ürk- "to arise, to lift", ürküt- "to lift", uttur "before, opposite", uza- "to lengthen", uzun "long", uzut- "to make (someone) sleep", üç "three", üçür- "to abolish", ülem "death", ülis- "to be divide", ürek "heart", ürgen- "to learn", ürget- "to teach", üy "house", üz- "to tear", üzge "other". 
- Some sounds events were determined in "U-Ü" items, e.g. Syncope [urtamak "middle finger" (< urta "middle" + tarmak "finger"; unduk kaptır (< unudup kalıptır) "I forget" cf. Shor. poltır (< poluptır) ], Anaptyxis (Chin. lóng 龙 > YUyg. ulu /ull “thunder; dragon”), Epentez (ürçik ürçük "homeware, fur" = OldT üçik "fur-skin, fur-coat"), Vowel fusion (uşkuç< işke "two" üç "three"), Metathesis [YUyg. ürgen- "to learn" (OldT ögren-), YUyg. ürget- "to teach" (OldT ögret-)], olgan "little boy" (OldT oglan), ulgak "kid/young goat" (OldT oglak)], Assimilation (YUyg. undup kalıptır > unduk kaptır "I forgot").

- Some other phonetic features in "U-Ü" items are as follows:

a. $-d-=-z$ - phonetic change: ET yıdruk = SUyg. uzruk "fist", ET udl- = SUyg. uzu- "to sleep", ET $\imath d u k$ "sent, i.e. dedicated to God; sacred" = cf. SUyg. uzukçı "dedicated to God", ET $u$ dit- = SUyg. uzut- "to make (someone) sleep".

b. - Ş $=-s$ phonetic change: ET ülüş= SUyg. ulus II "share, part", ET üleş- = SUyg. ülis"to be divide", ET ulaş-= SUyg. ulas- co-operative of verb ula- "to join".

c. /ag/, /1g/, /ug/ preservation of voice group: ET ula: $\breve{g} 2$ = SUyg. ulağ "pack livestock", SUyg. ulağlı̆ "having pack livestock", ET ulug = SUyg. ulug "big, great", ET urug "seed, pip; decendants, clan" = SUyg. urug "kinship"

- Some lexical determinations related to "U-Ü" items are as follows: üzüt- "lit. broken the soul; to die" derived from $\ddot{u} z$ - verb is determined to only survive in Yellow Uyghur. Furthermore, ündün "east" word also is determined to only survive in Yellow Uyghur. 


\section{GİRIŞ}

“Sarı Uygurca Üzerine Etimolojik Denemeler: U-Ü Maddeleri” adını taşıyan bu çalışma, daha önce tarafımdan yayımlanan "Sarı Uygurca Üzerine Etimolojik Denemeler" (Ayazlı, 2016: 290-313) adlı çalışmanın devamı niteliğindedir. 2016 yılında yayımlanan ilk makalede, S. Y. Malov ve E. R. Tenişev’in sözlüklerinin “A” maddesi üzerinde durulmuştur. 2017 yılında yayımlanan diğer çalışmalarda ise söz konusu sözlüklerin "E” (2017: 1320-1338) ve "I-İ” (2017: 148-171) maddelerine yer verilmiştir. Malov ve Tenişev’e ait çalışmaların ünlüyle başlayan maddelerinin alfabetik sırayla yayıma hazırlanması planlanmaktadır. $\mathrm{Bu}$ nedenle bu çalışmada, "U-Ü” maddeleri ele alınmıştır.

Makale, üç bölüm olarak düzenlenmiştir. İlk bölüm olan Giriş bölümünde kısaca yöntem üzerinde durulmuştur. İkinci bölümde, S. Y. Malov (1957) ve E. R. Tenişev (1976) tarafindan yayımlanan çalışmaların "U-Ü” maddeleri incelenmiştir. Malov ve Tenişev tarafından Rusça olarak yayımlanmış çalışmaların sözlük bölümlerindeki "U-Ü” maddeleri Türkiye Türkçesine çevrilmiş ve bu maddelerdeki sözcükler gerekli etimolojik açıklamalarla desteklenmiştir. Malov ve Tenişev tarafından ya da farklı zamanlarda diğer araştırmacılar tarafından yapılan etimolojilere de yer verilmiştir. Çalışmanın amacı Sarı Uygurca üzerine etimolojik bir sözlük oluşturmak olduğu için Türkçe sözcüklerin Eski Türkçedeki biçimlerine diğer tarihî ve modern dönemlerdeki biçim ve anlamlarına da yer verilmiştir. Sözcüklerin Eski Türkçedeki biçimleri için Sir Gerard Clauson'un etimolojik çalışmasından yararlanılmıştır. Sistem olarak zaman zaman Malov ve Tenişev'in çalışmalarından farklı bir yol izlenmiştir. Örneğin, Malov'un çalışmasında uju “onun ucu” gibi madde başı verdiği çekimli yapılar, bu çalışmada ilgili maddelerin $(u c ̧+u>u j u)$ altında toplanmıştır. uçuncu / uçuncul gibi aynı maddede yer alan farklı morfemlerle türetilmiş sözcükler ayrı maddeler altında verilmiş ve bu çalışmada Malov ve Tenişev'in çalışmalarından ayrılan madde başları dipnotlarla belirtilmiştir. İkinci bölüme ait bazı madde başlarında (ukar-, ul, ulă̆, ul̆gan, ulır-, un-, urğak, usuruk, uya, uyin, undur-, ur- I, uruğ, ursan, uşko, uzl- vb.) yalnızca sözcüğün anlamı verilmiş ve diğer Türk dilleri ile karşılaştırma yapılmamıştır. Bunun nedeni, bu madde başlarının "U-Ü” maddeleri ile eş zamanlı olarak yayıma hazırlanan "O-Ö” maddelerinde yer alıyor olmasıdır. Bu yüzden şöyle bir sistem izlenmiştir: "U-Ü” madde başı ile başlayan sözcüklerin anlamı verildikten sonra bk. ifadesi ile ilgili maddeye ("O-Ö” maddelerine) gönderilmiştir. (Örneğin; ulăg yük hayvanı bk. olağ). Üçüncü bölümde ise elde edilen bulguların değerlendirildiği sonuç bölümü yer almaktadır.

\section{U-Ü MADDELERİ}

\subsection{U Maddesi}

u türkülerde vezin gereği kullanılan ses.

u o, şu, öteki bk. $o$ 
uca kuyruk sokumu kemiği, sırt, arka, kıç, kalça, peglerge ucasın salğaktro "beylere (şölende) (hayvanın) kuyruk sokumu kemiğini dağıtır”, ucasında su var nimi-dro "onun arkasında su vardı" bk. oca “ay." Tenişev, 1976: 193.

ucak bk. uzak (Tenişev, 1976: 217)

uç uç, ucin (ismin -i hâli) uju, ucu "onun ucu", uju $u^{l}$ onun ucu $\|$ Etim.: ET uç "uç, son" (ED 17b), TMEN II: 576, EDAL II: 1482, ESTY 611, Kar. uç “uç, kenar” DLT I: 44, Çăg. uç "uç” NevS 1029, Kıp. uç “uç, uç taraf” KıpTS 291, Çuv. věś “son, uç” ÇuvRS 76, KrçMlk. uç “uç” KrçMlkTS 416, Kaz. uş “ay.” KazTS 589, Tat. oç “ay.” TatRS 415, Kır. uç “ay.” KırTS 778, Az. uc "ay.” AzRS 302, Trkm. uç "ay.” TrkmRS 685, YUyg. uç “uç, son, nihayet” YUTS 434, Öz. uç "son, uç" UzED 338, Tuv. uş "uç, son” TuvTS 112, Hak. us "uç, tepe, doruk" HakTS 550, Alt. uç “uç, son, nihayet” AltTS 191.

uç- uçmak bk. uş- ||Etim.: ET uç- "uçmak (kuş için), ölmek (amir için)" ED 19b, EDAL II: 1483, ESTY 613, Kar. uç-“uçmak” DLT I: 163, Çağ. uç- "ay.” NevS 1029, Kıp. uç- "ay.” KıpTS 291, Çuv. věś- “ay.” ÇuvRS 76, Az. uç- “ay.” AzRS 302, Trkm. uç- “ay.” TrkmRS 686, KrçMlk. uç- "ay.” KrçMlkTS 416, Kaz. uş- “ay.” KazTS 589, Tat. oç- "ay.” TatRS 417, Kır. uç- “ay.” KırTS 778, YUyg. uç- “ay.” YUTS 434, Öz. uç- “ay.” UzED 338, Tuv. uş- "uçmak” TuvTS 111, Hak. krş. uçuh- "uçmak, havalanmak” HakTS 550, Alt. uç- “ay.” AltTS 191.

uça uyluk (koyunun arka ayağı); insanların omuzundaki kürek kemiği; omuz, uçaga karap-tro “(o) geriye baktı” bk. uca

uçıgırma on üç \|Etim.: uç "üç" + ıgırma "yirmi"

uçon otuz bk. üçön ||Etim.: uç “üç” + on “on”, Tuv. üjen "ay.” TuW 287.

uçuncu üçüncü $\ddot{\mathrm{u}}^{2} \mathrm{bk}$. $\ddot{u} c ̧ \ddot{u} c \ddot{u}$

uçuncul üçüncü ||Etim.: uç+uncul

uçur- sırt üstü düşmek; devirmek, alt üst etmek, y1kmak bk. üçür-.

udorcı pağma (Bud.) (oçir veya bacra) işaret paleti, hükümdarlık asası

ufkur devenin hörgücü (Tenişev, 1976, 217)

uğ- öğütmek, kırmak (değirmende), azıktı takan üğte "tahılı una ögüttü”, tegermenin ma uğup-to "unu da öğüttü” (harf. değirmenin) ||Etim.: ET $u v$ - "ufalamak, ovuşturmak, toz haline getirmek" ED 4a-b, Kar. uw- "ufalamak” DLT I: 166, Çağ. üg- "un öğütmek” NevS 1033, Az. ov- "ovarak ince narin hâle getirmek" AzTS 2642, YUyg. krş. uğat- ugat- uvat-

1 Malov'un sözlüğünde ayrı madde başı olarak verilen $u j u$ "onun ucu” sözcüğü, uç “uç" sözcüğünün 3. tekil kişi iyelik eki almış biçimi olduğu için $u c ̧$ maddesinde verilmiştir.

2 Malov'un sözlüğünde aynı maddede verilen $u c ̧ u n c u$ ve $u c ̧ u n c u l$ sözcükleri için ayrı madde başları yapılmıştır. 
“öğütmek, ufalamak” YUTS 441a, Öz. krş. uvat- / uvala- "ufalamak” UzED 343, KazTat. $u v$ - "ovmak; parçalayıp ezmek" KazTS 309b, Kum. krş. uval- "parçalanmak, ufalanmak" KumTS 2011, Bşk. krş. uval- "parçalanmak, tuz buz olmak, un ufak olmak” BşkTS 665.

uğırlı- dökülmek, serpilmek (dağ için) ||Etim.: *uğlr-ll-bk. oğurll-

uğoça Çin. coğ.

uğur azğır aygır sürüsü bk. oğır, uğır kujgar, uğur koy "koyun sürüsü” (Tenişev, 1976: 217). uğur için bk. oğır "bir miktar, miktar (bir şeyin); sürü” maddesi azgır "aygır" için bk. Ayazlı, 2016: 309.

uj boğa (12 yaşındaki), uj yıl "boğa yılı" ||Etim.: ET ud "sığır” ED 34a, krş. EDAL II: 1484, ESTY 572, Çăg. uy "sığır” NevS 1032, YUyg. uy “öküz” YUTS 441, Alt. uy "inek” AltTS 195, Kir. uy “inek” KirTS 789.

ukar-: koy ukar- "koyun otlatmak" bk. okar- |Etim.: ET otgar- "hayvanı otlatmak, otlatmaya götürmek” (ED 48a) eyleminin söz içi -t-'si düşmüş biçimidir. bk. otkar-

ul o bk. ol

ula- bağlamak, birleştirmek (Tenişev, 1976: 217) ||Etim.: ET ula- “eklemek” DLT III: 255, Osm. ula- "eklemek, birleştirmek" TS VI: 3939, Çağ. ula- "ulaştırmak, uzatmak" NevS 1030, Kıp. ula- "bitiştirmek, ulaştırmak” KıpTS 292, Kır. ula- "uçlarıyla bitiştirmek” KırTS 781, Trkm. ula- "birleştirmek, bağlamak" TrkmRS 659, YUyg. ula- "bağlamak, birleştirmek, eklemek" YUTS 436, Öz. ula- “ay.” UzED 339, Tuv. ula- “ay.” TuvTS 111, Hak. ula- II "bağlamak, uçları düğümlemek" HakTS 545, Alt. ula- "uçlarını bağlamak, birleştirmek" AltTS 193.

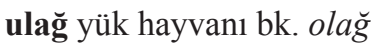

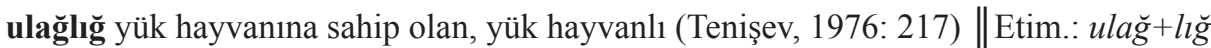

ulak küçük oğlak bk. ulgak

ulas- ula- "bağlamak" eyleminin işteşi (Tenişev, 1976: 217) ||Etim.: ula-s-, ET ulaş“eklenmek, katılmak" ED 154a, Kar. ulaş- "ulaşmak, bitişmek” DLT I: 189, Çağ. ulaş“ulaşmak, kavuşmak”, Kıp. ulaş- "erişmek, ulaşmak” KıpTS 292, Trkm. ulaş- "birleşmek, kavuşmak" TrkmRS 659, Kaz. ulas- "artarak devam etmek, sürmek” KazTS 584, YUyg. ulaş- "ekleşmek, bağlaşmak" YUTS 436, Öz. ulaş- "birbirini takip etmek” UzED 339, Hak. krş. ulas "birleştirme, bağlama” HakTS 546, Alt. ulaşs- "bağlamak, eklemek” AltTS 193.

ulgak oğlak, keçi yavrusu (1 yaşındaki) (Tenişev, 1976: 217) ||Etim.: uğul+ak> ulğak, ulğak sözcügüü, ET oglak sözcüğünün göçüşmüş biçimidir. ET oglak "keçi yavrusu, oğlak; genç erkek, erkek çocuk (bazı modern dillerde)” ED 84b, Kar. oglak “ay.” DLT I: 65, Çağ. 
oglak “ay.”, Kıp. oglak “ay.” KıpTS 203, Az. oğlak "ay.” AzTS 2603, KrçMlk. ulak "ay.” KrçMlkTS 417, Kır. ulak “ay.” KırTS 781, YUyg. oğlak "ay.” YUTS 293, Tuv. oolak "oğul, çocuk, oğlan çocuğu” TuW 227, Hak. oğlah "(bir yaşındaki) yabani keçi” HakTS 331, Alt. ulak “ay." AltTS 193, Yak. uolax: uolax oyuur "genç orman” YakRS 437.

ulğan küçük çocuk (erkek) bk. olğan $\|$ Etim.: oğul+an > (göçüşme yoluyla) ulğan. bk. oğlan

ulı / ulu Çin. lei 雷 "gök gürültüsü" (eski zamanda "ejderha”), ulı yll "ejderha yılı" (Tenişev, 1976: 217), ulu Şimşek Tanrısı ejderhanın adı, ulu kürkürigeş "gök gürültüsü”, tenir ulu kürkürigeş, yağıp tro "göğün ejderi gürledi ve yağmur yağdı", ak ulu bk. olu, lu, ulu/ulı (Malov, 1957: 129) bk. olu || Çin. lóng 龙, ET lu “ejderha” ED 763a, Sarı Uygurcada sözcük ön ses $-u$ - türemesi ile $u l u$ / ulı biçiminde görülmektedir. Bazı modern dillerde yaşar. Çağ. luy "ejderha", Kaz. ulu "on iki hayvanlı takvime göre beşinci yılın adı ejder" KazTS 585, Kır. uluu "on iki senelik hayvan devri takviminde beşinci yılın Çince adıdır (ejder)" KırTS 783, Tuv. ulu “ejderha” TuW 284, Alt. ulu “ejderha” AltRS 193.

ulır- yaşamak, bulunmak, kalmak, oturmak (Tenişev, 1976: 217) bk. olur- / olır-

ulis- bölünmek, taksim edilmek bk. ülis- ||Etim.: uli-s-

ulug (nadir kullanılan bir sözcük, genelde pezik sözcüğü kullanılır) büyük, ulu, yüce ||Etim.: ET ulug "büyük, ulu” ED 136b, Räsänen ulug sözcügünü $u l$ "temel”’ sözcügüne dayandırmıştır. (VEWT 513), Ayrıca bk. TMEN II: 536, EDAL II: 1494, ESTY 593, Kar. ulug "ulu, büyük, yüce” DLT I: 51, Osm. ulu "zengin, itibarlı, şerefli, çok büyük” TS VI: 3949, Çağ. ulug “ulu, büyük” NevS 1031, Kıp. ulug / ulu "büyük, ulu, yüce” KıpTS 292, Az. ulu "ay." AzRS 301, Trkm. ulı "ay." TrkmRS 660, KrçMlk. ullu "büyük” KrçMlkTS 417, Kaz. ul "ay." KazTS 585, Tat. olug “ay." TatRS 410, Kır. uluu "ay.” KırTS 783, YUyg. uluğ “ulu, yüce” YUTS 436, Öz. uluğ “büyük” UzED 340, Tuv. ulug “ay.” TuvTS 112, Hak. ulug “ulu, büyük, iri” HakTS 546, Alt. ulu "ay.” AltTS 193, Yak. uluu "büyük, ulu" YakRS 433.

ulus I halk, ulus, oy ulus "halk, ulus", oylığ ulus "bozkırda yaşayan halk" ||Etim.: Mo. ulus "ulus, halk, millet; devlet, ülke, şehir; hanedan" = ET uluş "halk, millet" ED 152, ET uluş sözcüğü Moğolcaya geçerek Moğolcanın ses yapısına uymuş ve ulus biçimini almıştır. Ayrıca Tü. $u l+{ }^{u}{ }_{S}$ etimolojisi için bk. Kaçalin, 2011: 1031, EDAL II: 1183, Eren, 1999: 22, TMEN I: 54, ESTY 592, Kar. uluş "köy, şehir" DLT I: 62, Osm. ulus "aşiret, halk, millet, kavim" TS VI: 3955, Çağ. ulus "halk” NevS 1031, Kıp. ulus "halk, millet” KıpTS 293, Trkm. ulus “ay.” TrkmTS 646, Kaz. ulıs “ay.” KazTS 585, Kır. ulut “ay.” KırTS 783, YUyg. ulus “1. halk, 2. vatan" YUTS 436, Öz. ulus "ulus” UzED 340, Tuv. ulus “ay.” TuW 284, Hak. ulus “halk, ulus" HakTS 547, Alt. ulus "ulus, halk" AltTS 193.

3 ul "temel" için bk. Battal, 1997: 79, ul "duvar temeli" için bk. DLT I: 48. 
ulus II pay, hisse, ulus sal̆gak-tro; peglerge ucasın salğak-tro "(et) dağıtıyor; beylere kuyruk kemiğini veriyor" ||Etim.: ET ülüş < üle-ş “pay, hisse” ED 153b, TMEN II: 546, Kar. ülüş “pay, hisse, bölüm, kısım” DLT I: 62, Çağ. ülüş “bir miktar, bir bölük” NevS 1033, Kıp. ülüş "pay, hisse" KıpTS 298, TT (ağ.) ülüş "komşuların birbirine gönderdiği yemek" DS XI: 4064, Trkm. ülüş “ay.” TrkmTS 654, KrçMlk. ülüş “ay.” KrçMlkTS 423, Kry. ülüş “ay.” KryTD 508, Kaz. üleş “ay.” KazTS 597, Kır. ülüş “zengin adamın civardaki halka yahut bir kabilenin diğer bir kabileye yahut bir bölge ahalisinin başka bir bölge ahalisine verdiği ziyafet” KırTS 794, YUyg. ülüş “pay, hisse” YUTS 445, Öz. ülüş “ay.” UzED 340, Tuv. üleş “paylaşma, bölüşme” TuW 287, Hak. ülüş “hisse, pay” HakTS 557, Alt. üleş “pay, hisse”.

umsı öküz, sı̆̆ır ${ }^{4}$

Umu bk. Lağlı Umu (Özel isim)

un ses, kisenin un anda enxtu-dro "insanın sesi orada yayılır (ses verir)" bk. on II

un on bk. on I

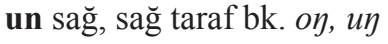

un- I çıkmak, büyümek, yükselmek, şuitından un- "duvar deliğinden yağmur çıkmak", sen ksege un! "sen evlen!”, at ungen "ünlü” (harf. "adı açığa çıkan, yayılan kişi”), yaxşı kise ma ungey, yus kise ma ungey", as un-, toy un- "şölen yapmak, ziyafet düzenlemek", unuk keptro "görünmüş, ortaya çıkmış”, pelek kün unina! "(bu gün) hediye verme günü olsun!" (ölüyü (cesedi) yakmak ve toprağa gömmek için evden çıkarmak) bk. on-

un- II çağırmak, davet etmek, toyga un- “düğüne çağırmak” ||Etim.: krş. ET ünte“(insanlara ve kimi hayvanlara) seslenmek, (birini) çağırmak” ED 180a, Kar. krş. ünde“çağırmak” DLT I: 273, Çağ. krş. ünde- "çağırmak, haykırmak” NevS 1034, Trkm. krş. ünde- "1.yöneltmek, 2. çağırmak” TrkmTS 655, YUyg. krş. ünde- "1. söylemek, demek, 2. çağırmak, davet etmek, 3. seslenmek, imdat istemek” YUTS 445, Öz. krş. ündä- "seslenmek, çağırmak, davet etmek" UzED 340, Bşk. krş. önde- "çağırmak, seslenmek, davet etmek" BşkTS 462, KazTat. krş. önde- "1. birisini bir iş yapması için teşvik etmek, nasihat etmek, 2. bir iş yapmaya davet etmek, çağırmak” KazTatS 212, Alt. krş. ünde- "ses vermek” ATS 197, Hak. krş. ünne- "ses çıkarmak, seslenmek” HakTS 558.

un- III nehirden geçmek, sunı unalmă̆aş "nehirden geçmesi mümkün olmayıp"

unco inci bk. ünci

Uncoğmo Tibetçe kadın adı

Malov'un çalışmasında bu sözcük soru işareti ile verilmiştir.

yaxşı kise ma ungey, yus kise ma ungey cümlesinin sözlükte çevirisi yapılmamıştır. Cümle "iyi kişi de kötü kişi de ortaya çıksın" biçiminde Türkçeye aktarılabilir. 


\section{Uncuğmo bk. Uncoğma}

Uncuğmu bk. Uncoğma

\section{Uncumu bk. Uncoğma}

undır- bk. undur-

unduğan tapınak binası (krş. semi "bitişik nizamlı tapınak”)

undula- / undulla- öldürmek, katletmek (iç organlarını çıkarıp), ündüllairnıり, ündüllernıฑ ${ }^{6}$ (ismin -In hâli).

undun 1. doğu, 2. üst, yukarı, önce, undunnın işke tıs “üsten (önden) iki diş” bk. ündün

undur- çıkmak, çıkarmak, serbest bırakmak, tıske per pisır etkaş undurvalğaş "kazanda biraz pişirip çıkarıp", pelnıり musırnı Geser-Xan undurvalğaş mayğıstın per baçın kıtırvaptro "Geser Han kılıcını çıkarıp Mangıs'ın başını ayırdı”, kezgunı undurine! "Kıyafetini çıkar! Soyun!”, xulu undırvat! “Çardağı kur, düzenle!” ||Etim.: un-dur- bk. öndür-, ündür-

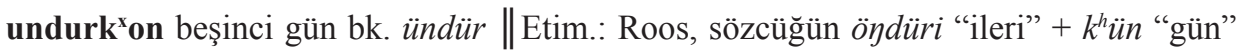
yapılarının büzülmüş biçimi olduğunu ifade eder (WestY 386). öydüri krş. ET ö $+d \ddot{u ̈ r}+t i$ “önde, ileride, doğuda” ED 181b.

unduruster- çıkmak, dışarı çıkmak; atmak, fırlatmak || Etim.: un-dur-us-ter-

ungumatarçi (Tarçin?) Uygur erkek adı

unkuş (Boz. Uyg.) girtlak

unlenmo Çin. hikâyedeki zenginlik, servet ismi

unşı- okumak; söylemek, telaffuz etmek, pıtı̆̆ unşı- "kitap, mektup okumak, okumay1 sökmek", lom unşı- "(Budizmde) duayı yayvan yayvan okumak", orsay unşı- "Budist dua

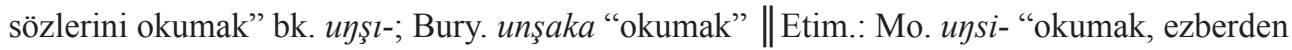
okumak” Lessing 877a /MTS 1351b.

Unşıpo Çin. hikâyedeki (Uygur ?) erkek adı

unşıt- okumayı öğretmek, okutmak; dua okuması için görevlendirmek \|Etim.: Mo. ujsi+ Tü. $-t-$

unut- unutmak, unutup > undup, untup, unutına" "unutuyor" (unutu-dır-na?) bk.

6 Malov'un çalışmasında ündüllairnı̀, ündüllernıり ayrı madde başı yapılsa da undulla- kökü ile ilgili olduğu için bu maddede verilmiştir.

7 Malov tarafindan unutına (unutu-dır-na?) sözcüğü “unutmuş” olarak çevrilmiştir. Ancak - $u$ zarf-fiili ve dır eki Sarı Uygurcada şimdiki zaman için kullanılmaktadır. 
undukkal-, men unduk kaptır "“unutmuşum" Tenişev, 1976: 218 |Etim.: ET unit- "unutmak" ED 179b, ESTY 597, Kar. unit- unut- "unutmak” DLT I: 215, Az. unut- "ay.” AzRS 302, Trkm. unut- “ay.” TrkmTS 648, YUyg. unut- "ay.” YUTS 438, Öz. unut- “ay.” UzED 341, Kaz. umit- "ay." KazTS 585, Kum. unut- “ay." KumRS 338, Kır. unut- "ay.” KirTS 784, Tat. ontt- "ay." TatRS 411, Tuv. ut- "ay." TuW 285, Hak. undu- "ay." HakTS 547, Alt. unut- "ay." AltTS 194.

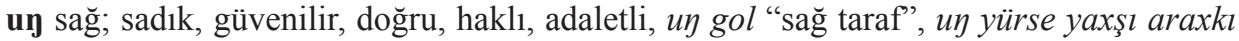
kegir "sağa gidersen iyi votka getir" bk. oy, un

ungış gırtlak bk. unkuş

Ungumbo Serıp Uygur erkek adı.

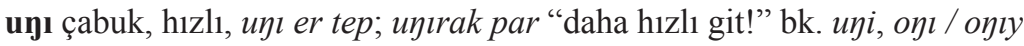

ułıyer- (ołar- ?) tamir etmek, düzeltmek, iyileştirmek ||Etim.: Malov, sözcüğün oyarsözcüğünden değişmiş bir biçim olduğunu düşünmüş olmalı ki parantez içerisinde ve soru işareti ile oyar- sözcügünü vermiştir.

uni bk. uךı

ūşs- okumak bk. unşı-

ur I soluk, nefes; yaşam, ömür, ur alu-dro "nefes alıyor" $\|$ Etim.: Moğ. agur "nefes, hava, atmosfer" MTS 28b / Lessing 17b.

ur II erkek giysisi (ceket)

ur III $(u r<$ erür $) n i-u r$ "bu nedir"

ur IV ur piğ veya ur piğım "kötü memur" (Tenişev, 1976: 218)

ur- I yatırmak, koymak, yerleştirmek; sanmak, zannetmek, yuğın ur- "gem vurmak", arkasınga ker yunak urmas mi-dro "(Tanrıya adanmış atların) sırtına kirli keçe koymaz",

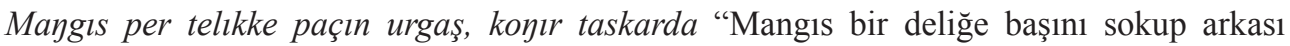
dişarda", pız ur- "biz (çuvaldız) batırmak" bk. or-

ur- II biçmek, doğramak, kesmek (otu), ot urğala (urğıla) parti "ota (ot biçmeye) gitti" ||Etim.: ET or- "biçmek (ot vb.), ekip biçmek (ekinleri)" ED 194b, ESTY 468, Çağ. or“biçmek” NevS 980, YUyg. or- “ay.” YUTS 297, Öz. or- “ay.” UzED 196, Trkm. or- "ekinleri orakla biçmek” TrkmTS 490, KrçMlk. or- “ay.” KrçMlkTS 310, Kaz. or- “ay.” KazTS 415, Kır. or- "ay.” KırTS 599, Tuv. ur- “dökmek, serpmek” TuW 284, Hak. or- "(ekin) biçmek, kesmek” HakTS 337, Yak. (ağ.) or- "1. Çıkarmak, 2. yarım daire şeklinde kesmek” (Yıldız, 2015: 365)

8 unduk kaptır $<$ unudu-p kal-ıptır 
urcat: şare urcat (?) “bir Uygur’un zamanı ifade etme şekli”: toxkus minik

urci bk. urçi (Tenişev, 1976: 218)

urçi eşya, yol eşyası, bagaj ${ }^{9}$

urçit soy ağacı, şecere, köken, soy

urçum anlam, mana

urçut bk. urçit

urğak orak bk. orğak

urğıla- bağırmak, haykırmak, inlemek bk. urglat-, urğula-\|Etim.: *urğglla-, Kar. $u r \imath+l a$ - "bağırmak, sesini yükseltmek" DLT I: 309.

urğlat- 1. kendini yiyip bitirmek, üzüntü içinde olmak, şə๖na (şənnı) appargaş, kulıgeş urğlatkakdro "fotoğrafları alıp birbirine ekleyip üzüntüye sebebiyet veriyor", 2. çığlık koparmak: ay!, vay!; 3. çoğaltmak, üretmek ||Etim.: urğula-t-

urğula- inlemek, sızlamak bk. urğıla-

urğut-: uzuk urğut- "yalan söylemek, yalan konuşmak"

urkut- bk. urukut-

ursan bk. orsan

urtamak orta parmak ||Etim.: urta "orta" + tarmak"parmak"

uru- I sarmak, sarmalamak, oro, oru- "sarılmak, dolamak" bk. ora-, orap, orop, orup, urup ||Etim.: Moğ. oriya- "bağlamak, sarmak, kuşatmak, dolamak, döndürmek, örmek, çevirmek, yuvarlamak” MTS 965b/Lessing 618a (Ayazl1, 2015: 108). Trkm. ora- "bir şeyin etrafinı sarmak" TrkmTS 490, YUyg. ora- "1. ambalajlamak, paket yapmak, 2. sarmak, 3. yumaklamak" YUTS 298, Öz. ora- "sarmak" UzED 196, KKlp. ora- "sarmak" KKlpRS 497, Kaz. ora- "sarmak” KazTS 415, Kır. oro- “dürmek, sarmak, dolamak” KırTS 599, Tuv. oraa- "sarmak, dolamak" TuW 227, Hak. ora- "sarmak, dolamak, sarmalamak" HakTS 337, Alt. oro- "sarmak" AltTS 140.

uru- II ${ }^{\mathbf{1 0}}$ gem vurmak, yügen ap-tro alğaş, atka urup-tro “dizgini alıp atı dizginledi”"| Etim.: Moğ. uru- "yırtmak, parçalamak; vurmak” Lessing 885b / MTS 1364b. krş. ur- I maddesi.

uruğ akrabalık; soy, nesil, urug darıg (ikileme) “akraba” bk. uruk II, oruğ.

9 "Yol eşyası, bagaj” anlamı için bk. Tenişev, 1976:

10 Malov'un çalışmasında uru- I ile aynı maddede verilen uru II eylemi iki ayrı fiil olduğu için bu çalışmada ayrı madde başı yapılmıştır. 
uruk I 1. ip, urgan Mo. urğa "kement” 2. bağırsak (koyunun bağırsağ1, şaman törenlerinde) ||Etim.: ET ur-uk ${ }^{11}$ “ip” ED 215a, Osm. krş. urkan" “urgan” TS VI: 3966, Trkm. krş. urgan "yün, ip vb. nesnelerden yapılan kalın ip" TrkmRS 649, Hak. uruh "kement"13 HakTS 549, Şor. uruk "kement" ŞorS 122.

uruk II akrabalık bağı, hısım, akrabalar bk. uruğ

uruk- şişmek, çıkmak, yükselmek, urukop par- "hareket etmek, ilerlemek"; teyir vucin uruku-dro "gökyüzüne çıkıyor”, Radloff I, 1833. Şor. ürük- bk. ürk-

urukut- sürdürmek, devam ettirmek, solıskon taygar paş azak urkutkek-tro "töreni yarın sabah sonlandırıyor" bk. urkut- ||Etim.: uruk-ut-

urusta- atlamak, firlamak; yükselmek, çıkmak, uzğanmas ulug turk uzganıp-tro, urustağaş 'oto!' digeş tenirge ürküvadıp-tro 'uyanmayan dev uyandı firlayıp 'oto!' diye gökyüzüne uçup gitti”||Etim.: *urus +ta-

us- $(<$ ous- ?) çok istemek, can atmak ||Etim.: ET us- "susamak" ED 241a, Kar. us“susamak” DLT I: 166.

usa (söz uzatımı) mende dal va usa, e vosa ... at par usa, kus var usa "hayvanım olsa ve hatta büyük baş hayvanım (sığırım) olsa" \|Etim.: polsa $>$ olsa $>$ osa $>$ usa.

usta- I benzemek, gibi olmak (ismin -i ve -e hâli ile), seminge tuz yok posa sunı ustagak-

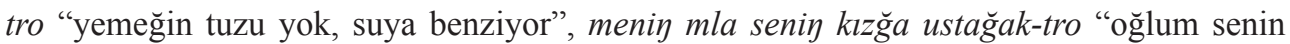
kızına benziyor (güzelliği bakımından)", Orl'on Şukçan yil ustagan (ak) mınıp-tro "Orlon Şukçan hızla (yel gibi) ak atına bindi”, taltakını usta- "ölen kişinin ruhuna benzemek”, pu kız mlağa ustey-dır "bu kız delikanlıya benziyor".

usta-II kapmak, yakalamak, tutmak \|Etim.: Kaz. usta- "tutmak, ele geçirmek, yakalamak" KazTS 588

ustas- benzemek (bazı nesneler için) ||Etim.: usta-s-

ustoğla-: klymă̆a ustoğla- (küfür)

usu kendisi bk. $u z$

11 Clauson, uruk sözcüğünün "başka bir şeyin üstüne konulmuş bir şey” anlamında büyük olasılıkla $u r$ - fiilinden türediğini ifade eder (ED 215a).

12 Eren, Orta Türkçe urgan sözcüğün uruk “ip, urgan” sözcüğünden -(a)n küçültme eki ile türediğini ifade eder (Eren, 1999: 424). Eren, çağdaş Türk diyalektlerinde geçen uruk adının $u k r u k$ (ukuruk) biçiminden geldiğini de ifade etmiştir.

13 Clauson, Hak., Tuv.'daki "urgan, kement” vb. anlamlı uruk sözcüğünün $u k r u k$ 'un ikincil biçimi olduğunu savunur (ED 215a). 
usun ${ }^{14}$ uzun bk. vusun (?), uzun.

Ustunba Şıkça Tova (Buda adı). Stonba Şaxca Tova

usuruk mideden gazın yayılması bk. osırık

uş üç, uş uştiり tokus “üç kere üç dokuz” bk. üş.

uş- bk. $\ddot{u} c ̧-$

uşko keçi, teke bk. eske “bir yaşındaki keçi” Ayazlı, 2017: 1331.

uşkuç yaklaşık üç ||Etim.: işke "iki” + üç "üç" > *lşkış >

uşta- kapmak, yakalamak, tutmak bk. usta-

ut $\mathbf{I}$ ateş bk. ot II

ut II ot bk. ot I

utağ memur şapkası (boncuklu şapka) krş. otuğat "tavus kuşu tüyü” (Çinli memurların şapkasındaki süs)

utor karşı; orta (?), utorğa koynı sola “ortadaki koyunu bağla” bk. utur, otur

utorma kırmızı tüyler (Çinli memurların şapkalarına yatay pozisyonda takılan) bk. uturma

utta- ölmek (çocuk için), ati mla uttasa "çocuk ölse"

uttur önünde, karşısında; ortasında, içinde: uturınğa “(onun) önünde” ||Etim.: ET utru "karşı, karşısında", *utur- "karşı çıkmak" fiilinin kısaltılmış zarf-fiil eki almış biçimidir (ED 64a-b), ESTY 610, Kar. utru “önce, karşı, orta” DLT I: 68, Çăg. utru "karş1, karşılık”, Kıp. utru "karşı, karşılık” KıpTS 294, Kry. utru "karşı, karşıda” KKS 115, YUyg. uttur "doğru, düz" YUTS 440, Tuv. udur "karş1" TuW 281, Hak. udur "karş1, ters" HakTS 544, Alt. odura "karşıt; ters, karşıdan gelen” AltTS 192, Yak. utarı "1. doğruca, karşı; karşısına, aksine, 2. karşısında, karşı; dosdoğru, 3. aykırı, muhalif, zıt” YakRS 446.

utuk sımık koyunun ayağındaki kemik bk. otuk

uturma calalığ $\breve{g}^{15}$ kıymetli taşlar geçirilmiş çerçeve bk. utorma

ux kun panna- Çin. “kitabı yeniden yazmak kâğıda dökmek” bk. panla-

$\mathbf{u}^{\mathbf{x}}$ ot bk. ot

14 Malov, sözcüğü soru işareti ile vermiştir.

15 cala + lığ "püsküllü, saçaklı" 
uy çabuk, hızlı || Etim.: Malov, uy sözcüğünü uүı "ç̧abuk, hızlı" sözcüğünden gelişmiş bir biçim olarak gösterir.

uya yumurta bk. oya

uyin / yin oyun bk. oin

uynağıș oyun ||Etim.: uyna- $\breve{g} ı S$

uynas- oynamak, flört etmek, cilve yapmak bk. oynas-

uyrat Uygurlara ait boy / kabile bölümü.

uz (Boz. Uyg.) boğa, öküz bk. uj

uz: $u z u^{16} /$ uzi "kendisi", uzumis "kendimiz", uzuler "kendileri”, uzum (Boz. Uyg.) "kendim", uzunınkl 17 "kendi” bk. $\ddot{u} z$

uz- ayırmak, koparmak, yırtmak, kesmek, per uzuvalğaş "biraz yırtıp", azagın uzgen (< üzgen) tügete "tamamlandiktan sonra" bk. $\ddot{u} z-$

uza- uzun olmak, uzamak (Tenişev, 1976: 218) ||Etim.: ET uza- "uzun olmak veya uzamak" ED 281a, ESTY 570, Osm. uza- "uzaklaşmak" TS VI: 4049, Çağ. uza- "uzamak", Trkm. uza- "uzamak" TrkmTS 652, YUyg. uza- "uzaklaşmak" YUTS 443, Öz. uza“taşınmak, gitmek, uzaklaşmak” UzED 344, Kaz. uza- "uzaklaşmak” KazTS 585, Kır. uza“uzaklaşmak” KırTS 792, Tuv. uza- "uzamak" TuvTS 113, Hak uza- "uzamak, uzun olmak" HakTS 553, Alt. uza- "uzamak, devam etmek" AltTS 196, Yak. uhaa- "uzamak (boy ve yükseklik olarak)” YakRS 443.

uzak uzak bk. ozak

uze kendisi bk. $u z u$

uzegen- ${ }^{18}$ değiştirmek

uzen uzun bk. uzin, uzun.

uzgen azagın uzgen tügete "bütün bunlardan sonra" ||Etim.: uz-gen

uzğan- uykudan uyanmak, uyanık kalmak, uyumamak bk. ozğan-

uzır-: tay uzır- "dua etmek" (Tenişev, 1976: 218).

16 Malov'un çalışmasında $u z$ sözcüğü değil de $u z$ sözcügüünün üçüncü tekil kişi iyelik eki almış biçimi olan $u z+u$ "kendisi” sözcüğü madde başı yapılmıştır.

17 uzunınkı sözcüğü Malov'un çalışmasında ayrı madde başı olarak verilse de $u z$ kökünün çekimli biçimi olduğu için $u z$ maddesi altında toplanmıştır.

18 Malov, soru işareti ile uzgen biçimini de parantez içerisinde gösterir. 


\section{uzin uzun bk. uzun}

uzruk yumruk ||Etim.: ET yıdruk “yumruk” ED 892b, Kar. yudruk “ay.” DLT III: 42, Çağ. yumruk "ay.", Kıp. yumruk "ay." KıpTS 329, Az. yumrug "ay.” AzRS 371, Trkm. yumruk "ay.” TrkmTS 710, KKlp. cudırık “ay.” KKlpRS 259, Kaz. judırık “ay.” KazTS 185, Kır. cuduruk "ay." KırTS 230, Nog. yumırık "ay.” NogRS 449, Tuv. çuduruk "ay." TuvTS 26, Hak. nuzuruh “ay.” HakTS 326, Alt. cuduruk “ay.” AltTS 65, Yak. suturuk “ay.” YakRS 346.

uzu- uyumak, uzumasa uzuma "uyumak istemiyorsan uyuma!", usutım? "Uyudun mu?" bk. ozl-

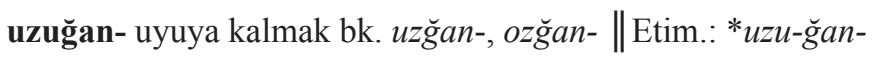

uzuk I yalan, uzuk et- "yalan söylemek", uzuk etpe "yalan söyleme” \|Etim.: ET ezük "yalan, hile” ED 285a, KKlp. ösek "dedikodu, iftira” KKlpRS 514, Kaz. ösek "giybet, dedikodu” KazTS 432, Kır. ösök “dedikodu, yerme, çekiştirme” KırTS 616.

uzuk II: $u z u \breve{g} ı n ~ u z u$ derin uykuya dal ||Etim.: uzu-k, ET $u d \imath k$ "uykulu, mahmur" (ED 46b)

uzukçı Tanrıya adanmış, Tanrıya adama $\|$ Etim.: $u z-u k+c ̧ \iota<* \imath d-u k$-çı ET krş. $\imath d u k$ “tanrıya gönderilmiş, tanrıya adanmış; kutsal, mübarek” ED 46a, EDAL I:611, Çuv. krş. yěrěx “1. din. put (kötü ruhun sembolü olan), 2. küfür sözü namussuz, alçak”, Kır. krş. ıyık "kutsal, mukaddes" KırTS 362, Tuv. krş. ıdık "mukaddes, mübarek" TuvTS 56, Hak. krş. ızıh II "1. ırmak, dağ, kır veya vadi ruhu, 2. tapınılan (dağ, ağaç, hayvan vb.) şey”, 3. kutsal, mukaddes" HakTS 207, Alt. krş. ıyık "mit. 1. nehrin, dağın, ovanın ruhu, 2. tapınma nesnesi (mesela, kurban sunulan ağaç, dağ)" AltTS 142, Yak. krş. ıtık I "kurban; kutsal, mukaddes" YakRS 532.

uzuma ü uyuma odası || Etim.: uzu-ma "uyuma" + $\ddot{u}$ “ev, oda"

uzun uzun, per kol uzun-dro "(onun) bir kolu uzundur" "Etim.: uza-n > uzun, ET uzun "uzun” ED 288b, Kar. uzun “ay.” DLT I: 77, Çağ. uzun “ay.”, Çuv. vărăm "ay.” ÇuvRS 69, Hal. uzun "ay." HalW 211, Az. uzun "ay.” AzRS 300, Trkm. uzın "ay.” TrkmRS 657, YUyg. uzun "ay." YUTS 443, Öz. uzun "ay." UzED 344, KKlp. uzın "ay.” KKlpRS 673, Kry. uzun “ay.” KryTD 507, Kaz. uzun "ay.” KazTS 582, Kır. uzun “uzun, uzunluk” KırTS 792, Tat. ozın "ay." TatRS 409, Tuv. uzun "ay.” TuvTS 113, Alt. uzun “uzun, yüksek” AltTS 196, Hak. uzun "ay." HakTS 553, Yak. uhun "uzun (boy için, zaman için)” YakRS 445.

uzunnıka uzun vadede, gelecek zamanda $\|$ Etim.: $u z u n+n \imath+k a$

uzur- takip ettirmek (Tenişev, 1976: 218) ||Etim.: Tenişev, uzur- fiilinin uza- eyleminin ettirgeni olduğunu ifade eder.

uzut ölü insanların ruhu, hasta insanların ruhu, pozı ta uzut ta kıştau geyşanğa ündürüptro "onlar ölü beden ve ruhları çarşıya (pazara) taşıdılar, götürdüler" bk. üzüt 
uzut- yatırmak, uyutmak || Etim.: uzu-t-, ET udıt- “harf. birini uyutmak” ED 45a, Kar. udit“uyutmak” DLT I: 207, Çağ. uyut- “ay.”, TT uyut- “ay.”, Kaz. uyıt- “mayalamak” KazTS 584, YUyg. uyut- "mayalamak, ekşitmek" YUTS 442, KKlp. uyıt- "1. mayalanmasına yardımc1 olmak, 2. mec. dikkatini çekmek” KKlpRS 674, Kır. uyut- “uyu- eyleminin ettirgeni” KırTS 792, Hak. uzut- "uyutmak, uyumasını sağlamak" HakTS 554, Yak. utut- "uyutmak” YakRS 446.

\section{2. Ü Maddesi}

ü ev, üte "evde”, ütekl “evdeki, eve ait olan” ||Etim.: ü sözcüğü, ev sözcüğünün çeşitli sesli değişimleri sonucunda görülen biçimidir: $e w>\ddot{u} w>\ddot{u} w i>\ddot{u} y>\ddot{u} \mathrm{bk}$. $\ddot{u} y$

üç üç, üç yüz “300” ||Etim.: ET üç “üç” ED 18b, TMEN II: 577, ESTY 641, Kar. üç “ay.” DLT I: 35, Çağ. üç “ay.” NevS 1033, Kıp. üç “ay.” KıpTS 297, Çuv. viśě “ay.” ÇuvRS 81, Hal. üç "ay.” HalW 211, Az. üç “ay.” AzRS 307, Trkm. üç “ay.” TrkmTS 654, Kaz. üş "ay." KazTS 601, KrçMlk. üç “ay.” KrçMlkTS 422, Kry. üç “ay.” KryTD 507, Tat. öç “ay.” TatRS 743, Kır. ̈̈ç “ay.” KırTS 793, YUyg. üç “ay.” YUTS 444, Öz. üç “ay.” UzED 338, Tuv. üş “ay.” TuvTS 115, Hak. üs “ay.” HakTS 560, Alt. üç “ay.” AltTS 196, Yak. üs “ay.” YakRS 458.

üç- uçmak bk. uç-, uş-

üçekteg (?) iyileştirme, geliştirme

üçon otuz ||Etim.: ̧̈̈̈ “3” + on “10”, Tuv. üjen "otuz” TuvTS 114

üçön bk. üçön

üçüki üçü, üçükse, üçükise “onların üçü” ||Etim.: ̈̈ç “3” + üki (addan ad yapan ek), ET üçegü “üçü, üçü birlikte” ED 25b, Çağ. üçegü “üç tane” NevS 1033, Kıp. üçöv “üçü birden, üçü beraber” KıpTS 297, KrçMlk. üçev "üç kişi” KrçMlkTS 422, Kry. üçöv "üçü birlikte” KryTD 507, Kaz. üşev “üç adet” KazTS 601, Kır. üçöö “üç kişi, her üçü” KırTS 793, Tat. öçev “ay.” TatRS 744, Yak. ühüö “üçü, üçü birlikte” YakRS 458.

üçüm (Boz. Uyg.) üzüm bk. öcüm

üçüncilık üçüncü, üçüncü (şey, madde) ||Etim.: üç+ünci+lık, TT üçüncülük, Trkm. üçüncilik “üçüncülük” TrkmTS 601.

üçünçö (Tib.) Gümüş Budanın adı (?)

üçünçö bk. üçüncü

üçüncü üçüncü ||Etim.: üç+üncü, ET üçünç “üçüncü” ED 29a, TMEN II: 581, Kar. üçünç “ay.” DLT I: 131, Çağ. üçünç “ay.” NevS 1033, Az. üçüncü "ay.” AzRS 307, Kry. üçüncü “ay.” KryTD 508, Kaz. üşinşi “ay.” KazTS 602, Tat. öçĕnçĕ “ay.” TatRS743, YUyg. 
üçünci “ay.” YUTS 444, Öz. üçinci “ay.” UzED 338, Tuv. krş. üşkü “ay.” TuW 290, Hak. üçı̌ncĭ “ay.” HakTS 555, Alt. üçinci “ay.” AltTS 196, Yak. ühüs “ay.” YakRS 458.

üçür- yok etmek, ortadan kaldırmak, paralamak, parçalamak (örneğin; kurt kuzuyu parçaladığında); saldırmak, hücum etmek, tertin koydan üş üçürvadıp-tro "kurt üç koyuna saldırdı" bk. uçur- ||Etim.: üç-ür-, ET öç-ür- "söndürmek (ateş vb.)” ED 30b, Çağ. öçür“ay.”, Trkm. öçür- “ay.” TrkmTS 501, KrçMlk. öçür- “ay.” KrçMlkTS 315, Tat. üçer- “yok etmek” TatRS 755, Kır. öçür- “ay.” KırTS 607, YUyg. öçür- “ay.” YUTS 303, Öz. öçir“ay.” UzED 193, Tuv. öjür- "söndürmek” TuW 232, Şor. üjür- "söndürmek, kapatmak (elektrik için)” ŞorS 123, Alt. öçür- "söndürmek” AltTS 142, Yak. öhör- "yok etmek, ortadan kaldırmak" YakRS 290.

ügde- dua etmek $\|$ Etim.: * üg+de-

ügüs nehir, Kara ügüs "Kara nehir” coğ. (Çin. Xoan-xo "Sarı nehir”) ||Etim.: ET ögüz “nehir” ED 119b, EDAL I: 613-614, Kıp. ögüz “ay.” KıpTS 209, Hak. üüs “ay.” HakTS 561.

ülem ölüm bk. öl- ||Etim.: ül-em, ET ölüm “ölüm” ED146a, Çağ. ölüm “ay.”, Kıp. ölüm “ay.” KipTS 211, Az. ölüm “ay.” AzRS 238, Trkm. ölüm “ay.” TrkmTS 503, KrçMlk. ölüm “ay.” KrçMlkTS 317, YUyg. ölüm “ay.” YUTS 305, Öz. ölim “ay.” UzED 195, KKlp. ölim “ay.” KKlpRS 509, Kaz. ölim “ay.” KazTS 427, Kır. ölüm “ay.” KırTS 610, Tat. ülem "ay.” TatRS 749, Tuv. ölüm “ay.” TuvTS 85, Hak. ölı̈m “ay.” HakTS 349, Alt. ölüm “ay.” AltTS 143.

üli < uli > (dinî) anıt, (kurdeleli, sopadan yapılmış) abide, Tenişev uli / üli "Şaman töreni sırasında kullanılan kurdeleli sırık" 217

ülis- bölünmek, taksim edilmek, bir şeyi kendi arasında bölmek, taksim etmek, yizdı ülis- "kumaşı bölmek, parçalara ayırmak" ||Etim.: üli-s-, ET üleş- "eşit olarak paylaştırmak, bölüştürmek” ED 154a, Kar. üleş- “ay.” DLT I: 189, Osm. üleş- “ay.” TS VI: 4062, Çağ. üleş“ay.”, Kıp. üleş- “ay.” KıpTS 297, Çuv. valeś- “ay.” ÇuvRS 63, TT (ağ.) üleş- “ay.” DS XI: 4062, Trkm. üleş- “ay.” TrkmTS 654, KrçMlk. üleş- “ay.” KrçMlkTS 423, Kaz. üleş- "ay.” KazTS 597, Tat. öleş- “ay.” TatRS 739, Öz. üleş- “ay.” UzED 339, Tuv. üleş- “ay.” TuW 287, Hak. üles- “(birlikte) bölmek, (birlikte) ayırmak” HakTS 556, Alt. üleş- "paylaşmak, bölüşmek” AltTS 197, Yak. ülles- “paylaşmak” Pekarskiy, 1928: 3118.

ülür- öldürmek ||Etim.: ül-ür-, ET ölür- “öldürmek” ED 151a, Tuv. ölür- “ay.” TuW 232, Yak. ölör- "öldürmek, boğazlamak (av hayvanı, büyükbaş hayvan)” YakRS 285

ülüs- bölmek, paylaşmak bk. ülis-

ün- çıkmak, doğmak, ırk ünse sen mayartağ kıl "eğer mutluluk alameti varsa gitmeye hazır ol!", purkan ün- "çiçek hastalığına yakalanmak; yayılmak, dağılmak; büyümek, genişlemek; çıkmak, peyda olmak", çindan ünse "şehirden çıksa", tajğar kün üngen tügete 
kokkaş maina "yarın sabah gün doğumundan sonra uykudan kalkıp yola koyul!", ak üngen "deve" (?), ırk karap-tro ünmin-dro "fal baktı kısmeti çıkmadı"

ünci küçük mercan, ünci tana "mercan (farklı ebatlarda)" (Tenişev, 1976: 218) ||Etim.: $y e n+c \ddot{u}<$ Çin. (cen çu) 真珠 zhen zhu, ET yinçü “inci”" ED 944b, Clauson sözcüğün ikinci hecesinin muhtemelen Çince $c h u$ "inci”" sözcüğünden ödünçleme olduğunu ifade eder. Kar. yinçü “inci” DLT I: 31, Çağ. ünçü “ay.” NevS 1034, Kıp. inçi / inçü / yençü / yençi "ay.” KıpTS 111, TT inci, Az. inci “ay.” AzRS 149, KrçMlk. inci “ay.” KrçMlkTS 229, Kır. cinci / incu “ay." KırTS 217, YUyg. ünce "ay.” YUTS 445, Tuv. çinçi “inci-boncuk” TuW 121, Hak. ninč̌ "ay." HakTS 324.

ünce tana mercan (Uygurların bilmediği inci) bk. ünci

üncüğma, üncuğmo Tibetçe kadın adı

ündö ölülerin gömüldüğü taraf ${ }^{19}$

ündüllairnıฺ, ündüllernın (ismin -In hâli) bk. undula-, undulla-

ündün doğu, ündünden "doğudan”||Etim.: Malov, sözcüğü soru işareti ile Çin. dun' (?) köküne bağlasa da ündün sözcüğü ET ö +dün "ön (tarafta bulunan), doğu” (ED 178a) sözcügüüün denkliğidir.

ündür: ündür-xon "beşinci gün” (bugünden) bk. undurkxon, ündür-xun.

ündür- 1. çıkarmak, yukarı çıkarmak, yukarı götürmek; övmek, göklere çıkarmak, Şamba mış undürüp-tro "Şamba (Burhan) kediyi yetiştirdi”, orsay ündür- "tütün (sigara) içmeyi bitirmek", minik ündür- "para harcamak", 2. çıkmak, yerinden oynamak, sakatlamak, kırmak (bel için); asılmak, yapışmak; alıp götürmek; kıvrılmak, bükülmek, pelın ündürvatkan-dro "beli yerinden oynadı" bk. öndür-

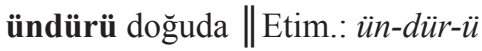

ünge- dikkatli dikkatli bakmak, gözlerini dikmek (?)

üngek: cigde üngek terik "ağaç"

ünger- / üngür- koymak, yerleştirmek (koyunu atın üzerine), koymak (köpeğin kâsesine herhangi bir şey) bk. ınger- \|Etim.: krş. Kır. öyör II "birisini veya bir şeyi önde giden atın üzerinde götürmek; bir şeyi kendisinin önüne eyere koyarak götürmek" KırTS 612, Alt. öyör- "eyerin ön tarafina oturmak” AltTS 143.

üntür- çıkarmak, yukarı çıkarmak, yukarı götürmek bk. ündür- 
ür üst, yukarı, üri tegip, kozı tegip “yukarı (tepeye) aşağı sıçrayıp”, azakın tejir ür polğan ${ }^{20}$ "ayağıyla tepmek, çifte atmak (neredeyse gökyüzüne kadar)" |Etim.: Çağ. ör "yokuş, yukarı" NevS 986, KrçMlk. ör “yükseklik, yüksek” KrçMlkTS 317, Kır. ör “üst” KırTS 614

\section{ürcorva isim (?)}

ürçi eşyalar, bagaj, yolcu eşyası $1^{21}$

ürçik bk. ürçük

ürçük kürk (Çin kumaşıyla kaplı beyaz koyun kürkü) ||Etim.: Sarı Uygurca ürçük sözcügünün kökünde yer alan -r sesi ikincil bir sestir. Sarı Uygurcadaki ikincil -r sesi için bk. erçik ürçik ürçük “ev eşyası, kürk”, erkes “ikiz”, ET içük "kürklü deri, kürklü giysi” (ED 24a), ürçük için bk. erçik maddesi Ayazlı, 2017: 1327.

ürek kalp (vücudun bir parçası) bk. örek ||Etim.: ET yürek "kalp; yürekli, cesur" ED 965a-b, Kar. yürek “yürek” DLT I: 41, Çağ. yürek “yürek”, Kıp. yürek “ay.” KıpTS 333, Hal. yirek "ay." HalW 226, Az. ürek "ay.” AzRS 305, Trkm. yürek "ay.” TrkmTS 713, YUyg. yürek “ay.” YUTS 472, KKlp. cürek "ay.” KKlpRS 269, Kry. yürek / ürek “ay.” KKS 117, Kaz. jürek "ay.” KazTS 190, KrçMlk. cürek "ay.” KrçMlkTS 162, Kır. cürök "ay.” KırTS 238, Tuv. çürek TuW 129, Hak. çürek “ay.” HakTS 111, Alt. cürek “ay.” AltTS 67, Yak. sürex “ay." YakRS 350.

ürgen çadırın kazığı; sığırları bağlamak için kazık ||Etim.: ör-gen, ET örgen "örme ip" ED 225b sözcügü ile ilgili olmalıdır. Kar. örgen "urgan” DLT I: 108, Osm. örgen "urgan, ip, yular” TTS V: 3117, Çağ. örge “çadır”, Kıp. örgen “urgan, ip, halat” KıpTS 211, Kry. örken “ip” KryTS 466, Tuv. örgen "kazık, sopa, değnek” TuW 234-235, Hak. örgen "kazık” HakTS 351, Yak. örgön “uzun, örülmüş deri ip” YakRS 288.

ürgen- öğrenmek |Etim.: ög(ü) $r+e-n-\sim \ddot{o g}+r e-n->$ ügren- > (göçüşme yoluyla) ürgen-, Malov sözcüğü ög "düşünce” köküne bağlamıştır. ET ögren- "öğrenmek” ED 114b, ESTY 496, Kar. ögren- “ay.” DLT I: 252, Çağ. örgen- “öğrenmek” NevS 986, Kıp. ögren- / ören“ay.” KipTS 209, Az. öyren- “ay.” AzRS 237, KrçMlk. üren- "ay.” KrçMlkTS 423, Kry. üren- “ay.” KryTD 509, Kaz. üyren- “ay.” KazTS 595, Tat. öyren- “ay.” TatRS 738, K1r. üyrön- “ay.” KırTS 800, YUyg. ögen- “öğrenmek” YUTS 303, Tuv. öören- “ay.” TuvTS 85, Hak. ügren- “ay.” HakTS 556, Alt. üren- “ay.” AltTS 198, Yak. üören- “ay.” YakRS 455.

ürget- öğretmek\|Etim.: ög(ü)r+e-t- ög+re-t- > ügret- > (göçüşme yoluyla) ürget-, ET ögret- “öğretmek” ED 114a, Kar. ögren- “ay.” DLT I: 261, Çağ. örget- “öğretmek”, Kıp. ögret- / öret- “ay.” KipTS 209, Az. öyret- “ay.” AzRS 237, KrçMlk. üret- “ay.” KrçMlkTS 423, Kry. üret- “ay.” KryTD 509, Kaz. üyret- “ay.” KazTS 595, Tat. öyret- “ay.” TatRS 738,

20 Malov, azakın teyir ür polğan cümlesinde geçen ür sözcüğü için ayrı bir madde başı yapmıştır; ancak sözcük ür "üst, yukarı" maddesi ile ilgili olduğu için tek bir maddede toplanmıştır.

21 Sözcüğün "bagaj, yolcu eşyası anlamı” için bk. Tenişev, 1976: 218. 
Kır. üyröt- “ay.” KirTS 800, YUyg. öget- “öğretmek” YUTS 304, Tuv. ööret- “ay.” TuvTS 85, Hak. ügret- “ay.” HakTS 556, Alt. üret- “ay.” AltTS 198, Yak. üöret- “ay.” YakRS 455.

ürı üst, yukarı, maygls ürı kop, kep-tro "Mangıs uykudan kalktı" bk. ör ||Etim.: ür-l, ET örü: "yukarıya, yukarı doğru”, ö:r- I "yükselmek, kalkmak" fiilinin zarf-fiil eki almış biçimi olan örü sözcüğü zarf olarak kullanılır (ED 197b), Osm. örü / öri "1. kalkık, dik, 2. yükseklik” YTS 169, Çağ. örü “yüksek, yükseklik”, Kıp. öre "ayakta durma” KıpTS 212, KrçMlk. öre "dik, yüksek” KrçMlkTS 317, Tuv. örü "yukarda, yukarıda” TuvTS 86, Alt. örö “yukarı, ileri” AltTS 144, Yak. örö “1. yukarı, yukarıya, 2. daha yukarıda” YakRS 288.

üri Saxkıs’ın güneyinde küçük bir yer, nehir adı

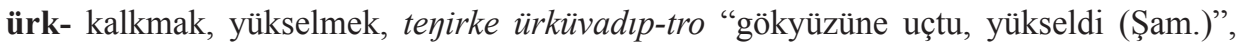
kalkmak, havalanmak; kanat çırpmak (kuşlar için), pu xumnı baştan gul xumnı başka ürk(k)eş xanığak-tro "bu kumlu tepeden diğer kumlu tepeye götürür” bk. örk- ||Etim.: ET ürk- “ürkmek, korkmak” ED 221a, Kıp. ürük- / ürk- "ürkmek, korkmak, çekinmek” KıpTS 298, Hal. hirk- "ürkmek (yalnızca hayvanlar için)” HalW 133, Trkm. ürk- "ay.” TrkmRS 672, YUyg. ürkü- “ürkmek” YUTS 446, KrçMlk. ürk- “ürkmek” KrçMlkTS 423, KazTat. örěk- "ürkmek” KazTatS 212, Hak. ürük- “ürkmek, korkmak, telaşlanmak” HakTS 560, Şor. ürük- "heyecanlanmak, koşmak" ŞorS 125, Alt. ürkü- "korkmak, ürkmek” AltTS 198, Yak. ürt- "ürkmek, korkmak (hayvanlar için)” Pekarskiy, 1928: 3175.

ürküt- yükselmek (rüzgâr için), yıl kelgeş ürkütkeş "rüzgâr yükselip geldi” (harf. rüzgâr yükselip gelip) ||Etim.: ürk-üt-ET ürkit- “ürkütmek, korkutup kaçırmak” ED 226b, Kıp. ürküt"bir dereceye kadar korkutmak, ürkütmek, kaçırmak" KıpTS 298, YUyg. ürküt- "ürkütmek" YUTS 446, KrçMlk. ürküt- “ürkütmek” KrçMlkTS 423, KazTat. örkĕt- “ürkütmek” KazTatS 212, Şor. ürgüt- "sevindirmek, memnun etmek, hoşnut etmek, keyiflendirmek” ŞorS 125, Alt. ürküt- “ürkütmek” AltTS, Yak. ürgüt- “ürkütmek, korkutmak” YakRS 456.

ürküt tap- başına kötü bir şey gelmek, yokluk çekmek\|Etim.: ürk-üp tap- > (gerileyici benzeşme yoluyla) ürküt tap-

ürle tẹir gökyüzü||Etim.: ür+le teyir

ürlex yüksek ||Etim.: ür+lex, Kaz. örli “yokuşlu, yamaçlı bayır” KazTS 431, Alt. krş. örleg “en yukarıda” AltRS 233

ürli- kalkmak, yükselmek bk. örle-

üş üç krş. uş

üşkö keçi bk. uşko

üşküç iki-üç bk. işke, üç ||Etim.: işke "iki” + üç “üç" > işküç > üşküç 
üt tele- borç, ödünç almak (halk etimolojisi ?) ||Etim.: tele-, ET tile- "aramak; istemek" ED 492a.

ütle-22 borç, ödünç almak, ütlete "borç aldı" bk. üt \|Etim.: üt+le-

üy ev, konut (daha çok metatezli biçimi yü kullanılır), ara üy "dolap”, ak üy "beyaz ev" (damadın düğün alayı ile geldiği gelinin veya yakınlarının çadırı)\|Etim.: ET ev "mesken, çadır, ev" ED 3b, ew > üw > üwi > üy, EDAL I: 577, ESTY 513, Çă̆. öy “ay.” NevS 988, Kıp. öy / ev /iv “ay.” KıpTS 213, Trkm. öy “ay.” TrkmTS 511, KrçMlk. üy "ay.” KrçMlkTS 423, Kry. üv “ay.” KryTD 510, Kaz. üy “ay.” KazTS 594, Tat. öy “ay.” TatRS 737, Kır. üy “ay.” KırTS 799, YUyg. öy “ay.” YUTS 309, Öz. üy “ay.” UzED 343, Hak. ib “ev, çadır” HakTS 217, Şor. üy “ev” ŞorS 125, Alt. üy “ev, çadır, barınak” AltTS 199.

üz kendi, kendisi, üz yüsünte olurıp-tro "kendi evinde yaşıyor" ||Etim.: ET öz "bir canlının iç bölümleri, öz; kendi” ED 278a, ESTY 506, Kar. öz “öz, kendi” DLT I: 45, Çağ. öz “ay.”, Kıp. $\ddot{z} z$ "ay.” KıpTS 214, Çuv. var "merkez, orta” ÇuvRS 64, Az. öz "ay.” AzRS 236, Trkm. öz “ay.” TrkmRS 498, YUyg. öz “ay.” YUTS 310, Öz. öz “ay.” UzED 200, KKlp. öz “ay.” KKlpRS 505, Kry. öz "ay.” KKS 93, Kaz. öz "ay.” KazTS 423, KrçMlk. öz "ay.” KrçMlkTS 319, Kır. öz “ay.” KırTS 618, Tat. üz "ay.” TatRS 745, Tuv. ös "ana atardamar” TuW 235, Hak. ös III hlk. "kendi” HakTS 352, Alt. ös: ös soluma “dönüşlülük zamiri” AltTS 144, Yak. üos I “merkez, orta, öz (ağaç için)” YakRS 455.

üz-23 parçalamak, yırtmak ||Etim.: ET üz- "yırtmak, parçalara ayırmak” ED 279b, Kar. üz- “(ip ve benzeri şeyleri) kesmek” DLT I: 165, , Osm. üz- “ay.” TS VI: 4134, Çağ. üz“kırmak” NevS 1034, Kıp. üz- "koparmak, kırmak” KıpTS 299, Az. üz- “yıpratmak, kırmak, gevşetmek” AzRS 304, Trkm. üz- "bir şeyi koparmak, parçalamak” TrkmTS 659, YUyg. üz“ay.” YUTS 448, Öz. üz- “ay.” UzED 344, KKlp. üz- “ay.” KKlpRS 687, Kry. üz- “ay.” KKS 117, Kaz. üz- “ay.” KazTS 593, KrçMlk. üz- “ay.” KrçMlkTS 424, Tat. öz- “ay.” TatRS 737, Kır. üz- "ay.” KırTS 800, Tuv. üs- "koparmak, yırtmak, ayırmak” TuvTS 115, Hak. üs- "ay." HakTS 560, Alt. üs- “ay.” AltTS 198.

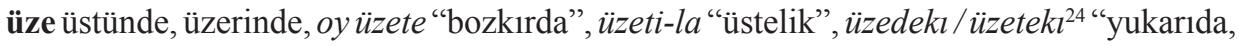
üzerinde", $\ddot{u} z e t i^{25}$ "üstünde, üzerinde" bk. üzi, yüze, üzü, öze,

üzeisi: elığnıฤ üzeisi “elin yan tarafı, avucun karşısı”.

Üzen (Şam.) İlah krş. Xermanns-Özen-Xan

üzge başka, diğer (nadir olarak kullanılır; daha çok toğur duyulur) ||Etim.: $\ddot{u} z+g e$, ET

22 Malov’un sözlüğünde ayrı madde başı verilen ütle "borç, ödünç; ütle(p) parti (?) "borç aldı" maddesi de ütlealtında birleştirilebilir.

23 Malov'un çalışmasında $\ddot{u} z(\ddot{u})$ - (< $\ddot{u} z$-) şeklinde madde başı olarak verilmiştir (Malov, 1957: 132).

24 Malov'un çalışmasında madde başı olarak verilmiştir.

25 Malov'un çalışmasında madde başı olarak verilmiştir. 
özge "başka, farklı” ED 285b, ESTY 508, Çağ. özge “ay.” NevS 988, Kıp. özge “ay.” KıpTS 214, Az. özke "ay.” AzRS 237, Trkm. özge "ay.” TrkmTS 514, YUyg. özge "başka, yabancı" YUTS 310, Öz. özge “ay.” UzED 200, KKlp. özge “ay.” KKlpRS 505, KrçMlk. özge “ay.” KrçMlkTS 319, Tat. üzge “ay.” TatRS 745, Kır. özgö “ay.” KırTS 619, Tuv. öske “ay.” TuvTS 86, Hak. öske “1. başka, diğer, 2. yabancı” HakTS 352, Alt. öskö “ay.” AltTS 145.

izi / üzü üzerinde, sumalnıり üzige "çantanın üzerinde”, üzüsünge "(onun) üzerinde, üstünde" bk. üze.

üzüt kötü ruh ||Etim.: üz+üt, ET özüt “insan ruhu” ED 281b, Clauson özüt sözcügüünün $\ddot{o z}$ "ruh" sözcüğü ile etimolojik olarak açıkça bağlantılı olduğunu ancak morfolojisinin belirsiz olduğunu ifade etmiştir. Kıp. üzüt “ölü” KıpTS 300, Hak. üzüt II “(halk inancında) can, ruh, ölen kişinin ruhu” HakTS 562, Alt. üzüt “mit. ölmüş insanın rüzgâr şeklindeki ruhu; hayvanlar ve insanlar gibi ruhun göze görünen maddi bölümü” AltTS 199.

üzüt-: Gu kseniๆ çanı üzütüp-tro "O kişi öldü (harf. "o kişinin Tanrısal ruhu kesildi)" ||Etim.: $\ddot{u} z-\ddot{u} t-$.

\section{SONUÇ}

Bu makalede, Malov (1957) ve Tenişev'in (1976) çalışmalarının sözlük bölümündeki "U-Ü" ile başlayan sözcükler, etimolojik olarak incelenmeye çalışılmış ve incelemenin sonucunda aşağıdaki sonuçlara ulaşılmıştır.

• "U-Ü" maddelerinde toplam 197 sözcük tespit edilmiştir. Bu sözcüklerden 135'i "U” maddesine 62'si de "Ü” maddesine aittir. "U ve Ü” maddeleri çerçevesinde Sarı Uygurca ve diğer Türk dilleri ile yapılan karşılaştırma sonucunda ortaya çıkan veriler şöyledir: Sarı Uygurca ile hem Kuzey hem de Güney Sibirya Türk dillerinde varlığını sürdüren 12 ortak Türkçe sözcük tespit edilmiştir: ulğak, ulug, uttur, uza-, uzruk, uzun, üç, üçür-, üleş-, ürek, ürgen-, ürget-. Sibirya Türk dillerinde tespit edilen Sar1 Uygurca 35 sözcügün 32'si Hakasçada, 30'u Altaycada, 27'si Tuvaca ve 18'i Yakutçada saptanmıştır.

- "U-Ü" maddelerinin söz varlığg doğrultusunda bütün modern dillerde ya da dil gruplarında kimi ses değişikleri ile varlığını sürdüren 23 ortak sözcük belirlenmiştir: $u c ̧$ "uç", uç- "uçmak", ula- "bağlamak, birleştirmek", ulgak "oğlak”, ulug "büyük”, ulus II "pay, hisse", unut- "unutmak", ürk- "kalkmak, yükselmek", ürküt- "yükselmek”, uttur "önünde, karşısında", uza- "uzamak", uzun "uzun”, uzut- "uyutmak”, üç “üç”, üçür- "yok etmek, ortadan kaldırmak", ülem "ölüm”, ülis- "bölünmek, taksim edilmek”, ürek "yürek”, ürgen“öğrenmek”, ürget- "öğretmek”, üy “ev”, üz- "parçalamak”, üzge “başka”.

- Sarı Uygurcada sözcüklerin hem art hem de ön ünlülü varyantları $(u \sim \ddot{u})$ eş zamanlı olarak kullanılabilir: ulis- ülis- "paylaşmak", undur- öndür- "çıkarmak, yukarı çıkarmak, yukarı götürmek", uşko üşkö "keçi”, uş üş “üç", uz- üz- "parçalamak, yırtmak", uçüç- "uçmak", uçur- üçür- "söndürmek". 
• "U-Ü” maddelerinde Sarı Uygurcaya ait kimi ses bilgisel özellikler tespit edilmiştir. "UÜ” maddelerinde görülen başlıca seslik özellikler ise şöyledir: ${ }^{26}$

a. $-d$ - foneminin -z-'ye değişmesi: ET yıdruk = SUyg. uzruk “yumruk", ET $u d d^{-}=$SUyg. $u z u$ - "uyumak", ET $\imath d u k$ "tanrıya gönderilmiş, tanrıya adanmış; kutsal, mübarek" = krş. SUyg. uzukçı "Tanrıya adanmış, Tanrıya adama", ET udıt- = SUyg. uzut- "yatırmak, uyutmak".

b. -ş foneminin -s'ye değişmesi: ET ülüş = SUyg. ulus II "pay, hisse”, ET üleş- = SUyg. ülis- "bölünmek, taksim edilmek", ET ulaş- = SUyg. ulas- "ula- 'bağlamak' eyleminin işteşi”"

c. /ag/, /1g/, /ug/ ses öbeklerinin korunması: ET ula:ğ 2 = SUyg. ulăg "yük hayvanı", SUyg. ulağlığ “yük hayvanına sahip olan, yük hayvanlı”, ET ulug = SUyg. ulug "büyük, ulu, yüce”, ET urug “tohum, çekirdek; döl, nesil, klan” = SUyg. urug "akrabalık"

d. Ses olayları: "U-Ü” maddelerinde tespit edilen ses olayları ise şunlardır:

Ünsüz Düşmesi: urtamak "orta parmak" sözcüğü urta "orta" + tarmak "parmak" kelimelerinden oluşmuş birleşik bir isimdir. Bu birleşik ismin ikinci kelimesinde (tarmak > tamak) sızıcı bir ses olan - $r$ - sesinin düştüğü görülür. Bir başka düşen ses ise - $p$ - sesidir. Sarı Uygurcada - $l$ sesiyle biten fiillere -tır eklendiğinde çoğunlukla - $p$ - sesi düşer. (men) unudu- $p$ kal-ıptır > unduk kaptır "unutmuşum”. krş. Şor. poltır ${ }^{27}$ (< pol-uptır) “olmuş, varmış", çattır ${ }^{28}$ $(<$ çat-ıptır) "yatmış, yerleşmiş".

Ünlü / Ünsüz Türemeleri: "U-Ü” maddelerinde dikkat çeken bir başka ses olayı ise ünlü ve ünsüz türemeleridir. Söz başı ünlü türemesine örnek olarak Çin. lóng 龙 > SUyg. ulı / ulu "ejderha" sözcüğü gösterilebilir. Ünsüz türemesine örnek olarak da söz içi ikincil bir -rsesinin türemesi gösterilebilir: Sarı Uygurca ürçik ürçük“ev eşyası, kürk” kelimesi, ET içük "kürklü deri, kürklü giysi”" kelimesinin denkliğidir. Dolayısıyla ürçik ürçük kelimesinde görülen söz içi -r- ikincil bir sestir.

Ünlü Kaynaşmast: Türkçede, birleşik kelime kuruluşlarında yan yana gelen iki ünlünün kaynaşarak tek ünlü durumuna gelmesine ünlü kaynaşması adı verilmektedir. uşkuç "yaklaşık üç, aşağı yukarı üç" sözcüğü de ünlü kaynaşması yolu ile (< işke "iki” + üç “üç”) oluşmuş bir sözcüktür.

Göçüşme: "U-Ü” maddelerine ait bir başka ses olayı da bir kelime içerisinde birbirini izleyen iki ünsüzün yer değiştirmesi, diğer bir deyişle göçüşme olayıdır: SUyg. ürgen“öğrenmek” (ET ögren- “öğrenmek”), SUyg. ürget- “öğretmek” (ET ögret- “öğretmek”), SUyg. ulğan "küçük çocuk (erkek)" (ET oglan "oğlan”), ulgak "oğlak, (1 yaşındaki) keçi yavrusu” (ET oglak “oğlak”).

26 Sarı Uygurcaya ait diğer seslik özellikler için bk. Tekin \& Ölmez 2003: 82-83-84.

27 Şor: Purungl töldüy sonda poltır "Geçmiş nesilden sonra" (Tekin \& Ölmez 2003: 80).

28 Şor: albattıg çon çattır "Bağımsız bir halk yaşarmış" (Tekin \& Ölmez 2003: 80). 
Benzeşme: Benzeşme, kelime içindeki bir sesin, boğumlanma noktası veya niteliği bakımından yan yana veya aralıklı duran bir başka sesle benzer veya eş duruma getirilmesi olayıdır. Eğer sonraki ses, daha önceki sesi kendi boğumlanma noktasına çekiyorsa bu benzeşme biçimine gerileyici benzeşme adı verilmektedir. unduk kaptır ve unuk keptro sözcüklerinde gerileyici benzeşme görülmektedir: SUyg. men unduk kaptır: unduk kaptır < unudup kal-ıptır "unutmuşum", unuk keptro < unup kel-iptro "görünmüş, ortaya çıkmış"

- "U-Ü” maddelerinde leksikolojik olarak dikkat çeken özellikler ise şunlardır: üzfiilinden türemiş olan üzüt- sözcüğü yalnızca Sarı Uygurcada "harf. ruhu kesilmek; ölmek" anlamıyla tespit edilmiştir; diğer Türk dillerinde sözcüğe rastlanmamıştır. Leksikolojik açıdan önem arz eden diğer bir sözcük ise ündün "doğu" sözcügüdür. Sözcük, yalnızca Sarı Uygurcada tespit edilmiştir.

\section{KISALTMALAR}

ağ.: ağız, Alt: Altayca, AltTS: bk. Naskali, Emine Gürsoy, Muvaffak Duranl1, ay.: aynı, AzTS: bk. Altaylı, S., bk.: bakınız, Bşk.: Başkurtça, BşkTS: bk. Özşahin, M. Çağ.: Çağatayca, Çin.: Çince, Çuv.: Çuvaşça, ÇuvRS: bk. Skvortsov, M. İ., DS: Derleme Sözlüğü, ED: bk. Clauson, Gerard, EDAL: bk. Starostin, S. vd., ESTY: bk. Sevortyan, ET: Eski Türkçe, Hak.: Hakasça, HakTS: bk. Naskali, Emine Gürsoy ve diğerleri, Hal.: Halaçça, HalW: Doerfer, G., harf.: kelimesi kelimesine, Kar.: Karahanlı Türkçesi, Kaz.: Kazakça, KazTat.: Kazan Tatarcası, KazTatS: bk. Öner, M., KazTS: bk. Koç, K., Kıp.: Kıpçakça, KıpTS: bk. Toparlı, R., Kır.: Kırgızca, KırTS: bk. Yudahin K. K., KKlp.: KaraKalpakça, KKIpRS: bk. Baskakov, 1958, KrçMlk.: Karaçay-Malkar Türkçesi, KrçMlkTS: bk. Tavkul, U., krş.: karşılaştırınız, Kry.: Karayca, KKS: bk. Çulha, T., KryTD: bk. Gülsevin S., Kum: Kumukça, KumRS: bk. Bammatov, Z. Z., Moğ.: Moğolca, MTS: Moğolca-Türkçe Sözlük, NevS: bk. Kaçalin, M., Osm.: Osmanlıca, OTWF: bk. Erdal, M., Öz.: Özbekçe, Şam.: Şamanizm, ŞorS.: bk. Tannagaşeva, N. N. K. vd., Tat.: Tatarca, Tib.: Tibetçe, TMEN: bk. Doerfer, G., Trkm.: Türkmence, TrkmRS: bk. Baskakov, N. A. 1968, TrkmTS: Tekin T. vd., TS: Tarama Sözlüğü, TT: Türkiye Türkçesi, Tuv.: Tuvaca, TuvRS: bk. Tenişev, E. R., TuvTS: bk. Arıkoğlu, E., Klara K., TuW: bk. Ölmez, M., UzED: bk. Dirks, W., VEWT: bk. Räsänen, Martti WestY: bk. Roos, M. E., Yak.: Yakutça, YakRS: Sleptsov, P. A., YUTS: bk. Necip, Emir Necipoviç, YUyg. Yeni Uygurca.

Finansal Destek: Yazar bu çalışma için finansal destek almamıştır.

\section{KAYNAKÇA}

Altaylı, S. (2018). Azerbaycan Türkçesi Sözlüğ̈̈, III Cilt. Ankara: Türk Dil Kurumu Yayınları. Atalay, B. (2006). Divanü Lûgat-it-Türk Tercümesi I (5. bs.) Ankara: Türk Dil Kurumu Yayınları. Ayazlı, Ö. (2015). Sarı Uygurcadaki Moğolca Ödünçlemeler. Uluslararası Sosyal Araştırmalar Dergisi $8(41), 103-11$. 
Ayazlı, Ö. (2016). Sarı Uygurca Üzerine Etimolojik Denemeler. International Journal of Languages Education and Teaching, 4 (2), 290-313.

Ayazlı, Ö. (2017a). Sarı Uygurca Üzerine Etimolojik Denemeler: I ve İ Maddesi. Gümüşhane Üniversitesi Sosyal Bilimler Enstitüsü Enstitüsü Elektronik Dergisi, 8 (21), 148-171.

Ayazlı, Ö. (2017b). S. Y. Malov ve E. R. Tenişev'in Sarı Uygurca Sözlükleri Üzerine Etimolojik Denemeler: E Maddesi. Elektronik Sosyal Bilimler Dergisi. Electronic Journal of Social Sciences 16, (63), 1320-1338.

Bammatov, Z. Z. (1969). Kumıksko russkiyy slovar'. Moskva 1969.

Baskakov, N. A., A.İ. İnkijekova-Grekul (1953). Hakassko-russkiy slovar'. Moskva.

Baskakov, N. A. (1958). Karakalpaksko-russkiy slovar'. Moskva.

Baskakov, N. A., Karriyev, B. A, Hamzayev, M. Ya. (1968). Turkmensko-russkiy slovar'. Moskva.

Battal, A. (1997). İbni-Mühennā Lügati. Ankara: Türk Dil Kurumu Yayınları.

Clauson, G. (1972). An Etymological Dictionary of Pre-Thirteenth-Century Turkish. Oxford: Clarendon Press.

Çulha, T. (2006). Karaycanın Kısa Sözvarlı̆̆. İstanbul: Dil ve Edebiyat Dizisi 6.

Dirks, W. (2005). Uzbek English Dictionary. The Central Asian Heritage Group.

Doerfer, G. (1963-1975). Türkische und mongolische Elemente im neupersischen I-IV. Wiesbaden.

Doerfer, G., Tezcan, S. (1980). Wörterbuch Des Chaladsch (Dialekt von Charrab). Budapeşt: Akadémiai Kiadó.

Erdal, M. (1991). Old Turkic Word Formation: A Functional Approach to the Lexicon I-II. Wiesbaden: Otto Harrasowitz Verlag.

Eren, H. (1999). Türk Dilinin Etimolojik Sözlüğ̈̈. Ankara: Bizim Büro Basımevi.

Gülsevin, S. (2016). Karay Türklerinin Dili (Troki Diyalekti). Ankara: Türk Dil Kurumu Yayınları.

Hüseynov, H. (1941). Azerbaydjansko-russkiy slovar'. Baku.

Kaçalin, M. S. (2011). Nevâŷ̉’nin Sözleri ve Çağatayca Tanıklar. Ankara: Türk Dil Kurumu Yayınları.

Koç, K., Bayniyazov, A., Başkapan, V. (2003). Kazak Türkçesi Türkiye Türkçesi Sözlügü. Ankara: Akçağ Yayınları.

Lessing, F. D. (1960). Mongolian-English Dictionary. Berkeley and Los Angeles: University of California Press

Lessing, F. D. (2003). Moğolca-Türkçe Sözlük. (Çev. Günay Karaağaç). Ankara: Türk Dil Kurumu Yayınları.

Malov, S. Y. (1957). Yazık jyoltıh uygurov: slovar i grammatika. Alma-Ata.

Naskali, E. G., Duranlı, M. (1999). Altayca-Türkçe Sözlük. Ankara: Türk Dil Kurumu Yayınları.

Naskali, E. G., Butanayev, V., İsina, A., Şahin, E., Şahin, L., Koç, A. (2000). Hakasça-Türkçe Sözlük. Ankara: Türk Dil Kurumu Yayınları.

Necip, E. N. (1993). Yeni Uygur Türkçesi Sözlüğü. (Çev. İklil Kurban). Ankara: Türk Dil Kurumu Yayınları.

Ölmez, M. (2007). Tuwinischer Wortschatz mit alttürkischen und mongolischen Parallelen. Tuvacanın Sözvarlığı Eski Türkçe ve Moğolca Denkleriyle. Wiesbaden.

Öner, M. (2009). Kazan-Tatar Türkçesi Sözlüğü. Ankara: Türk Dil Kurumu Yayınlar1.

Özşahin, M. (2017). Başkurt Türkçesi Sözlüğü. Ankara: Türk Dil Kurumu Yayınları.

Pekarskiy, E. K. (1907-1930). Slovar'yakutskogo yazıka I-III. 
Radloff, W. (1893-1911). Versuch eines Wörterbuches der Türk-dialecte (Opıt slovarya tyurskix nareçiy). I Cilt. Sankt Peterburg.

Räsänen, M. (1969). Versuch eines etymologischen Wörterbuchs der Türksprachen. Helsinki.

Roos, M. E. (2000). The Western Yugur (Yellow Uygur) Language, Grammar, Text, Vocabulary. Yayınlanmamış Doktora Tezi. Leiden: Rijks Üniversitesi.

Sevortyan, E.V. (1974). Etimologiçeskiy slovar'tyurkskih yazıkov. Moskva.

Skvortsov, M. İ (1982). Çăvaşla-vırăsla slovar'. Çuvaşsko-russkiy slovar’. Moskva.

Sleptsov, P. A (1972). Yakutsko-russkiy slovar'. Moskva.

Starostin, S., Dybo, A., Mudrak, O. (2003). Etimological Dictionary of the Altaic Languages. LeidenBoston: Brill.

Tannagaşeva, N. N. Kurpeşko, Akalın, Ş. H. (1995). Şor Sözlüğü. Türkoloji Araştırmaları.

Tavkul, U. (2000). Karaçay-Malkar Türkçesi Sözlüğü. Ankara: Türk Dil Kurumu Yayınları.

Tekin, T., Ölmez M., Ceylan, E., Ölmez, Z., Eker, S. (1995). Türkmence-Türkçe Sözlük. Ankara: Simurg Yayınları.

Tekin, T., Ölmez, M. (2003). Türk Dilleri Giriş (2. bs.). İstanbul: Dil ve Edebiyat Dizisi 2.

Tenişev, E. R., Todayeva B. H. (1966). Yazık jyoltıh Uygurov. Moskva.

Tenişev, E. R. (1968). Tuvinsko-russkiy slovar’. Moskva.

Tenişev, E. R. (1976). Stroy sarıg-yugurskogo yazıka. Moskva.

Türk Dil Kurumu (1972). XIII. Yüzyıldan Beri Türkiye Türkçesiyle Yazılmış Kitaplardan Toplanan Tanıklarıyla Tarama Sözlüğü. Cilt VI (U-Z). Ankara: Türk Dil Kurumu Yayınları.

Türk Dil Kurumu (1979). Derleme Sözlüğü. Cilt XI (U-Z). Ankara: Türk Dil Kurumu Yayınları.

Türk Dil Kurumu (1998). Türkçe Sözlük (9 bs.). Ankara: Türk Dil Kurumu Yayınlar1.

Yıldız, H. (2015). Eski Türkçe ile Yakutçanın Sözvarlı̆̆ının Ünlüyle Başlayan Sözcükler Bakımından Karşılaştırılması. Yayımlanmamış Doktora Tezi. İstanbul: Yıldız Teknik Üniversitesi, Türk Dili ve Edebiyatı Anabilim Dalı. Türk Dili Doktora Programı. Sosyal Bilimler Enstitüsü.

Yudahin, K. K. (1998). Kırgız Sözlüğ̈̈. Cilt II (K-Z). (Çev. Abdullah Taymas). Ankara: Türk Dil Kurumu Yayınlar1. 